\title{
News and the Overloaded Consumer: Factors Influencing Information Overload Among News Consumers
}

\author{
Avery E. Holton, M.A., and Hsiang Iris Chyi, Ph.D.
}

\begin{abstract}
News producers continue to increase their volume of production and delivery platforms in an effort to reach and maintain news consumers. However, consumers may not necessarily find more news desirable. Previous studies have suggested that information surplus can lead to negative outcomes for consumers, but research of outcomes related to news production and consumption has been scant. This study explores novel areas of news surplus and overload, empirically examining factors associated with the degree of perceived overload across a broad spectrum of news delivery platforms. The findings reveal that the majority of today's news consumers feel overloaded with the amount of news they are confronted with. Gender, news interest, and the use of specific news platforms and outlets predict the degree of that overload. News access through platforms and outlets such as computers, e-readers, and Facebook is positively associated with overload, whereas other platforms such as television and the iPhone are negatively associated with overload. Implications for media psychology and news consumption are discussed.
\end{abstract}

\section{Introduction}

A DVANCEMENTS IN DIGITAL TECHNOLOGIES have revolutionized the way information is produced and delivered, leading to a fundamental change unseen in human historythe vast oversupply of information. More than ever, people are reporting negative psychological and physiological responses to this change, ranging from increased levels of stress when working through email inboxes to anxiety about keeping up with multiple social network sites (SNSs) such as Facebook and Twitter. ${ }^{1,2}$

Communication scholars have recently begun examining how information, more specifically news content, might be contributing to these responses, ${ }^{3,4}$ noting that surpluses in information and the channels they are delivered across have profound implications for news media producers and consumers. ${ }^{5}$ The former continue to search for the best multiplatform delivery processes, while the latter sort through the resulting information heap, often turning their attention away at the first sign of oversupply., ${ }^{5,6}$ This is particularly apparent in news media, where consumers have reported increasing levels of news fatigue. ${ }^{7}$ In fact, despite a growing list of platforms and channels to access news by, some consumers report feeling helpless when it comes to seeking out news that is important to them. To them, news has become so ubiquitous, and they see consuming it as a task, or a chore, rather than as an opportunity for information acquisition. ${ }^{7}$ Similarly, many younger news consumers have evolved along with technology, adopting consumption behaviors previously unseen. Rather than relying on a single source for news, these consumers are tuned into the news nearly all day, constantly filtering content and arriving at news through various platforms. ${ }^{4}$

Given the amount of news content available today, it should not be surprising that news consumers, even the younger, evolving ones, are feeling overloaded with facts and updates. At a time when media organizations are struggling to remain relevant and profitable, the consideration of news content surplus-particularly, how to decrease it or the perception of it-is worth critical exploration.

This explorative study sought to expand the current conversation about information surplus to the scantly explored area of news content surplus and overload, asking first how overloaded today's news consumers feel and then considering the roles of demographics, news interest, and multiplatform consumption in those feelings. The results here advance current research by analyzing news surplus and feelings of overload among news consumers, paying particular attention to the increasing number of news delivery platforms these consumers are facing. 


\section{Literature Review}

Today's news media producers compete with each other as well as a growing contingent of independent content creators-think bloggers, microbloggers, and social media users-for user attention. ${ }^{8}$ This competition creates a saturation of news content and platforms that can contribute to what communication scholars have dubbed as psychological feelings of information overload. ${ }^{9}$ Broadly speaking, information overload occurs when the amount of available content becomes difficult for an individual to process, often causing negative feelings on the end of the consumer. ${ }^{10}$ That content comes in a variety of formats, though the Pew Research Center has shown that news alone has become overwhelming for consumers. At a time when the creation and sharing processes of news are undergoing dramatic shifts, considering the definition of news is important. Several communication scholars have argued that while the lines have blurred between news creators and news consumers, the definition of news itself has changed relatively little. News is represented by content, both new and contextualized, about a particular topic and distributed and/or verified through reputable sources. While the latter is the subject of much debate, it also suggests that news is now filtering through a number of channels and reaching consumers through a variety of platforms. ${ }^{11,12}$ At least one scholar has termed the news of today ambient news, suggesting that news content is omnipresent. ${ }^{12,13}$ While consumers can certainly seek out specific news content, escaping the news is as difficult as escaping advertisements. ${ }^{7}$

Noting an increasing amount of news content streaming through more outlets, including SNSs where news is differentiated between social status updates, ${ }^{14}$ Pew began asking questions about news overload in its 2008 biennial news consumption survey. The results indicated that 38 percent of American adults felt overloaded by the amount of news content available; women were more likely to feel overloaded, and those younger than 25 and older than 50 were more likely to share the feeling. ${ }^{15}$

\section{Multiplatform news consumption}

Pew more recently found more than 9 out of 10 American adults get their news content from multiple platforms, including local and cable television, Websites, radio, and local and national newspapers. ${ }^{16}$ The same study indicated that 46 percent of people use between four and six news sources daily. A more in-depth, ethnographic study from the Associated Press indicated that these patterns may be more common in younger age groups (18- to 34-years old), and are global in nature. ${ }^{4}$ News access platforms such as print newspapers, TV, computers, and smartphones drive toward news outlets such as local and national Websites and SNSs. Both have expanded dramatically over recent years, as news and information producers attempt to reach more consumers, especially younger ones. ${ }^{17}$

Noting the limited available research connecting information overload, news content, and multiplatform consumption, this study asked the following research question:

\section{RQ1: To what degree do people feel overloaded with the amount of news available?}

Before measuring the effect of multiplatform news consumption on news consumers' feelings of overload, it is es- sential to first examine the roles of demographic variables and news interest, because these variables may have an influence on those feelings. ${ }^{15,18}$ Therefore, this study asked the following research questions:

RQ2: What demographics, if any, influence the perceived degree of news overload?

RQ3: What role, if any, does news interest play in the perceived degree of news overload, after controlling for demographics?

After controlling for the influence of demographics and news interest, this study sought to uncover the association of different news technologies with news consumers' feelings of news overload. Therefore, the following research question was asked:

RQ4: What is the relationship between the use of different news delivery platforms and outlets and the perceived degree of news overload, after controlling for demographics and news interest?

\section{Method}

A Web-based survey of 767 adults (18+years old) was conducted on August 3-6, 2010, to examine U.S. Internet users' consumption of and attitudes toward online and traditional news media. The research firm, Survey Sampling International, provided the sample. The sample size of 767 yielded a standard sampling error of \pm 3.5 percentage points at the 95 percent confidence level (see Appendix 1).

\section{Survey instrument}

The survey focused on the use of, and attitudes toward, traditional and online news media. The questionnaire was developed according to the results of a focus group of 14 college students on their news consumption habits on multiple electronic devices (see Appendix 2). Revisions were made based on several rounds of pretests by potential respondents to ensure the validity of measurement.

To measure news overload, this study adopted the question from the Pew Research Center's 2008 Media Consumption Survey (Question 82F2), modifying the dichotomous response items (Yes/No) into a 5-point Likert scale to capture the variation in the degree of news overload. Respondents were asked, "Would you say you often feel overloaded with the amount of news available these days, or not?" $(1=$ Not at all; $5=$ A lot). Multiplatform news consumption was measured by asking respondents how many days a week (0-7) they access news on 10 different news platforms (i.e., print newspapers, TV, news magazines, desktop/laptop computers, netbook computers, the iPhone, other smartphones, e-readers, the iPod Touch, and iPad) and from five online news outlets (i.e., news portals, Facebook, Twitter, YouTube, and blogs.). News interest was measured on a 5-point scale by asking respondents how much they enjoy keeping up with the news, a question adopted from the Pew Research Center's biennial news consumption surveys. Demographic information on gender, age, education, and income also was collected.

\section{Data analysis}

Weighting. To ensure the demographic characteristics of the sample closely matched the demographic characteristics 
Table 1. A Comparison of the SAmple and the U.S. INTERNET POPULATION

\begin{tabular}{lccc}
\hline & $\begin{array}{c}\text { Internet } \\
\text { population } \\
\text { (percent) }\end{array}$ & $\begin{array}{c}\text { Sample } \\
\text { unweighted } \\
\text { (percent) }\end{array}$ & $\begin{array}{c}\text { Sample } \\
\text { weighted } \\
\text { (percent) }\end{array}$ \\
\hline Gender & & & \\
$\quad$ Male & 48.4 & 35.7 & 50.7 \\
Female & 51.6 & 64.3 & 49.3 \\
Age & & & \\
18-34 & 33.0 & 29.9 & 28.8 \\
35-54 & 41.2 & 45.2 & 44.6 \\
55+ & 25.8 & 24.9 & 26.6 \\
Income & & & \\
$\quad$ Less than \$50,000 & 36.6 & 64.3 & 35.8 \\
\$50,000-\$74,999 & 21.0 & 18.0 & 20.9 \\
$\quad$ \$75,000-\$149,999 & 30.7 & 14.7 & 31.0 \\
$\quad$ \$150,000+ & 11.7 & 3.0 & 12.4 \\
Education & & & \\
$\quad$ Did not attend college & 40.2 & 35.3 & 28.0 \\
$\quad$ Attended college & 29.8 & 33.4 & 31.3 \\
Graduated college plus & 30.0 & 31.3 & 40.7 \\
$\quad$ N & $223,672,000$ & 767 & 776 \\
\hline
\end{tabular}

aSource: Mediamark Research and Intelligence data published by the U.S. Census Bureau, based on adults $18+$ years old with Internet access as of fall 2008.

of the Internet population in the United States, this study weighted the data to gender and income (see Table 1).

Statistical tests. Because the outcome variable (information overload) was measured at the interval level, hierarchical multiple regression analysis ${ }^{19}$ was conducted to examine the effect of demographics, news interest, and multimedia news consumption on news overload. Based on the conceptual framework, the predictors were entered in three blocks: demographics (i.e., age, gender, education, and income), news interest, and news access through 10 platforms and five outlets. Multiplatform news consumption items were entered last, because their relationship with news overload, controlling for demographics, and news interest was the focus of this study. A multicollinearity test confirmed that no predictors were highly correlated with each other.

\section{Results}

\section{Perceived information overload}

When asked, "Would you say you often feel overloaded with the amount of news available these days, or not?," as indicated by Table 2, only 27.2 percent of the respondents indicated "not at all," suggesting that 72.8 percent of the respondents felt at least somewhat overloaded with the amount of news available today.

\section{Predictors of news overload}

A hierarchical regression analysis examined the effect of demographics, news interest, and multiple news consumption (with 15 individual items) on news overload. Despite as many as 20 predictors in the full model, statistical power reached 1.00 because of the relatively large sample size of 767 (Cohen's $f^{2}=0.15$, indicating a medium effect size). All three
Table 2. Perceived Degree of News Overload

\begin{tabular}{lr}
\hline & Percent \\
\hline 1 (Not at all) & 27.2 \\
2 & 13.5 \\
3 & 30.0 \\
4 & 20.1 \\
Total & 9.2 \\
\end{tabular}

"Would you say you often feel overloaded with the amount of news available these days, or not?"

Weighted $N=776$; mean $=2.71 ; S D=1.31$.

models were statistically significant, $p<0.001$. Table 3 summarizes the results.

To examine the impact of demographic variables on news overload, gender, age, education, and income were entered on the first step of the regression analysis. Gender (being female) was positively related to news overload $(\beta=0.093, p<0.05)$, whereas age $(\beta=-0.107, p<0.01)$ and income $(\beta=-0.092$, $p<0.05)$ were negatively associated with news overload.

News interest was entered at the second step of the regression analysis. In addition to gender, age, and income, news interest also was a significant predictor of news overload $(\beta=-0.078, p<0.05)$ - higher interest in following the news is negatively associated with the perceived degree of news overload after controlling for demographics.

To examine the relationship between individual news platforms and outlets and news overload, the 15 individual

Table 3. Summary of Hierarchical Regression Analysis for Variables Predicting News Overload

\begin{tabular}{lccc}
\hline Predictor & \multicolumn{3}{c}{$\beta$} \\
\hline Gender (female) & $0.093^{*}$ & $0.089^{*}$ & $0.091^{*}$ \\
Age & $-0.107^{* *}$ & $-0.093^{*}$ & 0.033 \\
Education & -0.014 & -0.009 & -0.035 \\
Income & $-0.092^{*}$ & $-0.088^{*}$ & -0.065 \\
News interest & & $-0.078^{*}$ & $-0.111^{* *}$ \\
News platforms & & & \\
$\quad$ Print newspapers & & & -0.053 \\
TV & & & $-0.084^{*}$ \\
News magazine & & & 0.032 \\
Computer & & & $0.097^{*}$ \\
Netbook & & & 0.031 \\
iPhone & & & $0.104^{*}$ \\
Other smartphones & & $0.176^{* *}$ \\
e-reader & & & 0.105 \\
iPod Touch & & & -0.079 \\
iPad & & & -0.055 \\
News outlets & & & $0.107^{*}$ \\
News portals & & & 0.005 \\
Facebook & & & 0.021 \\
Twitter & & & -0.005 \\
YouTube & & & \\
$\quad$ Blogs & & & \\
Model & & & \\
$R^{2}$ & & & \\
$R^{2}$ change & & & \\
\hline
\end{tabular}

Weighted $N=771$.

${ }^{*} p<0.05,{ }^{* *} p<0.01,{ }^{* * *} p<0.001$. 
news platforms/outlets items were entered into the last model. Results showed that among the 15 platforms/outlets, five were significant predictors of information overload. News access through computers $(\beta=0.097, p<0.05)$, e-readers $(\beta=0.176, p<0.01)$, and Facebook $(\beta=0.107, p<0.05)$ had a positive relationship with information overload, whereas TV $(\beta=-0.084, p<0.05)$ and the iPhone $(\beta=-0.104, p<0.05)$ had a negative association. Overall, this full model accounted for 13 percent of the variance in news overload $\left(R^{2}=0.13\right.$, $p<0.001)$. Cohen's criteria for effect size state that an $R^{2}$ between 0.09 and 0.25 is moderately strong. ${ }^{20}$

\section{Discussion}

This study provided a systematic examination of news overload and more accurately documented the extent to which people today feel overloaded with news. The regression analysis empirically examined the predictors of news overload in the context of multiplatform news consumption by incorporating the most comprehensive and up-to-date array of news platforms and outlets.

This study examined three groups of predictors (demographics, news interest, and multiplatform news consumption), as they presumably have an influence on news overload. The analysis identified gender (being female) as a significant predictor of news overload in all three models, confirming a previous research that indicated females report feeling more overloaded by the amount of news available. ${ }^{15}$ This finding also hints at previous research across disciplines that suggests women are faced with more daily multitasking than men, tend to adopt new technology with heightened levels of trepidation, and are more likely to report physical ailments stemming from overload. ${ }^{21,22}$ However, this research is far too scant to make generalizations. While recent data from the Pew Internet and American Life Project seem to suggest that women are adopting new technologies such as smartphones a bit more slowly than men, ${ }^{23}$ studies have not clearly indicated reasons for this adoption lag nor have they connected them directly with perceptions of overload. Future research should certainly explore gender differences, as they relate to feelings of news overload, especially with regard to emerging content delivery platforms.

This study also found that news interest is negatively associated with the perceived degree of overload, suggesting that news overload, despite being a consequence of content surplus, may be moderated by personal preference such as interest in following the news. Individuals who enjoy seeking the news may simply enjoy the plethora of availability ${ }^{24}$ or are capable of filtering out what they do not want to consume. $^{25,26}$ On the other hand, those who do not enjoy seeking out the news may feel overwhelmed-perhaps they do not care about news; they have received too much junk information, or they lack the long-term familiarity with the news, and thus have difficulties decoding complicated news stories. ${ }^{27}$

This study further provided a foundation for future research into news overload by analyzing a multitude of platforms where people might get news. Among the 15 news platforms and outlets measured, three (computers, e-readers, and Facebook) had a positive linkage with the level of perceived overload. Since computers are important tools for work purposes and a tremendous amount of news is accessible through computers, the results here are not surprising. As for e-readers, because of their relatively low adoption rate at the time of the study (5.7 percent among Internet users), future research should examine further its effect on news overload. Interestingly, news access through Facebook, the most popular SNS, may be causing undesirable consequences-overloading its users. Perhaps, Facebook users do not expect to or want to encounter news when interacting with friends on the platform. In other words, news might only get in the way when delivered through Facebook.

Television and the iPhone, on the other hand, were negatively associated with news overload. Previous research indicates that people watch television passively, using it as a means to pass time. ${ }^{28-30}$ Thus, thinking of television viewing as more of a relaxing experience is not much of a stretch. As for the iPhone, the most well-received smartphone on the market, perhaps it allows users to aggregate news and information sources more easily with apps-applications that directly link to news and information sources formatted specifically for the iPhone. Perhaps, it is seen as more enjoyable or easier to use than other devices (it is noted that other smartphones had no effect on alleviating information overload).

\section{Limitations and Conclusions}

In sum, news surplus forces consumers to tune some content out at the risk of wasting potential benefits, increase filtering habits and devices, cope with frustrations, develop stronger storage methods, change their learning techniques, or simply ignore the news all together. ${ }^{31-35}$ By examining the perceived levels of news overload on different delivery platforms, and by weighing factors contributing to perceptions of overload, news content producers might find stronger ways to reach and maintain consumers.

This study was based on data collected through an online survey. As a result, only Internet users were included in the analysis. In addition, only one survey question measured the construct of news overload. Single-item measures may be acceptable when questions or topics are straightforward or in exploratory studies such as this one. Conveying what exactly news overload is to survey respondents presents a difficult task that could be approached either with pointed definitions or through multiple measures that, when considered together statistically, serve as triangulated approaches to measuring news overload. More pointedly, future research should consider evolving sources and characteristics of news. Content delivery continues to move across emerging platforms and networks, appearing alongside more personal information. Researchers should consider the impact of such mixed delivery-one that places world news next to news about one's social circle, for example-on perceptions of overload. Finally, the iPad was launched only 4 months before the survey was administered, so it might be too early to gauge the relationship between iPad use and news overload.

Despite these limitations, this study serves as the first step toward a systematic examination of information overload, specifically the overload of news content, taking into consideration a wide array of emerging news platforms and outlets. Future studies should look into the interplay between news interest, multiplatform news use, and feelings of overload, as well as the plausible behavioral outcomes of such feelings and their social implications. 


\section{Author Disclosure Statement}

Neither researcher for this manuscript had any commercial support or other conflicts of interest.

\section{References}

1. Bregman P. (2012) Coping with email overload. Harvard Business Review. http://blogs.hbr.org/bregman/2012/04/ coping-with-email-overload.html (accessed May 28, 2012).

2. Swartz J. (2011) Social media users grapple with information overload. USA Today. http://usatoday.com/tech/news/ 2011-02-01-tech-overload_N.htm (accessed Feb. 2, 2012).

3. Hargittai E, Neuman WR, Curry O. Taming the information tide: perceptions of information overload in the American home. The Information Society 2012; 28:161-173.

4. Associated Press. (2008) A new model for news: studying the deep structure of young adult news consumption. http://slideshare.net/alirafat/studying-the-deep-structure-ofyoungadult-news-consumption (accessed Feb. 2, 2012).

5. Chyi HI. (2009) Information surplus in the digital age: impact and implications. In Papacharissi Z, ed. Journalism and citizenship: new agendas. New York: Lawrence Erlbaum/ Taylor and Francis, pp. 91-107.

6. Albarran AB. (2010) The media economy. Hoboken: Routledge.

7. Nordenson B. Overload! Journalism's battle for relevance in an age of too much information. Columbia Journalism Review (November/December) 2008; 47:30-42.

8. Holton A. (2012) The lights never go out: information overload, ambient news, and future practices. In McCombs ME, Hinsley AW, Kaufhold K, et al., eds. The future of news: an agenda of perspectives. 2nd ed. San Diego, CA: Cognella Academic Publishing, pp. 54-74.

9. Rogers EM, Agarwala-Rogers R. (1975) Organizational communication. In Hanneman, GL, McEwen WJ, eds. Communication behavior. Reading, MA: Addison-Wesley.

10. Bawden D, Holtman C, Courtney N. Perspectives on information overload. Association for Information Management Proceedings 1999; 51:249.

11. Lewis SC. (2010) Citizen journalism: motivations, methods, and momentum. In McCombs M, Hinsley AW, Kaufhold K, ed. The future of news: an agenda of perspectives. San Diego, CA: Cognella, pp. 59-76.

12. Hermida A. Twittering the news: the emergence of ambient journalism. Journalism Practice 2010; 4:297-308.

13. Hermida A. From TV to Twitter: how ambient news became ambient journalism. Journal of Media and Culture 2010; 13:1-10.

14. Grineva M, Grinev M. (2012) Information overload in social media streams and the approaches to solve it. Paper Presented at the 21st International World Wide Web Conference, Lyon, France. April 16-20, 2012.

15. Pew Research Center for the People and the Press. (2008) Key news audiences now blend online and traditional sources: audience segments in a changing news environment. http:// pewresearch.org/pubs/928/key-news-audiences-now-blendonline-and-traditional-sources 86:594-612. (accessed Dec. 20, 2011).

16. Purcell K, Rainie L, Mitchell A, et al. (2010) Understanding the participatory news consumer. Pew Internet and American Life Project. http://pewinternet.org/reports/2010/ online-news.aspx? $\mathrm{r}=1$ (accessed Dec. 20, 2011).

17. Ytreberg E. Extended liveness and eventfulness in multiplatform reality formats. New Media and Society 2009; 11:467-485.
18. Chyi HI, Yang MJ. Is online news an inferior good? Examining the economic nature of online news among users. Journalism and Mass Communication Quarterly 2009; 86:594-612.

19. Cohen J, Cohen P, West SG, et al. (2003) Applied multiple regression/correlation analysis for the behavioral sciences. 3rd ed. Mahwah, NJ: Lawrence Erlbaum Associates.

20. Cohen J. (1988) Statistical power analysis for the behavioral sciences. 2nd ed. Hillsdale, NJ: Lawrence Erlbaum Associates.

21. Oppenheim C. Managers' use and handling of information. International Journal of Information Management 1997; 17:239-248.

22. Cunningham T. (2011) Have you got Goldfish Memory Syndrome? A third of women can't remember their own phone number - and it's all down to information overload. The Daily Mail. http://dailymail.co.uk/femail/article-1381294/Goldfish Memory-Syndrome-A-women-remember-phone-number.html (accessed Feb. 2, 2012).

23. Smith A. (2012) Nearly half of American adults are smartphone owners: Pew Internet and American Life Project. http://pewinternet.org/Reports/2012/Smartphone Update2012/Findings.aspx (accessed May 9, 2012).

24. Frick R. (2010) Your mind and your money. Kiplinger's Personal Finance (online). http://kiplinger.com/podcasts/ investorpsychology/ (accessed March 9, 2011).

25. Mindich DTZ. (2005) Tuned out: why Americans under 40 don't follow the news. New York: Oxford University Press.

26. Savolainen R. Filtering and withdrawing: strategies for coping with information overload in everyday contexts. Journal of Information Science 2007; 33:611-621.

27. Thompson M. (2009) An antidote for web overload. Nieman Reports. http://nieman.harvard.edu/reports/article/101886/ An-Antidote-for-Web Overload.aspx (accessed Dec. 20, 2011).

28. Comstock G. (1980) Television in America. Beverly Hills, CA: Sage.

29. Kang M. Interactive in television: use and impact of an interactive program guide. Journal of Broadcasting and Electronic Media 2002; 46:330-345.

30. Webster JG, Phalen PF, Lichty LW. (2006) Ratings analysis: the theory and practice of audience research. 3rd ed. Mahwah, NJ: Lawrence Erlbaum Associates.

31. Cheng J, Sun A, Zeng D. Information overload and viral marketing: countermeasures and strategies. Lecture Notes in Computer Science 2010; 6007:108-117.

32. Douglis F. Information overload, 140 characters at a time. Institute of Electrical and Electronics Engineers Internet Computing 2009; 4:4-5.

33. Jones Q, Ravid G, Rafaeli S. Information overload and the message dynamics of online interaction spaces: a theoretical model and empirical exploration. Information Systems Research 2004; 15:194-210.

34. Wang Y, Zhang J, Vassileva J. Towards effective recommendation of social data across social networking sites. Lecture Notes in Computer Science 2010; 6304:61-70.

35. Wurman RS, Sume D, Leifer L. (2001) Information anxiety 2. Indianapolis, IN: Macmillan.

Address correspondence to: Avery E. Holton M.A.

University of Texas at Austin School of Journalism

1 University Station, A1000 Austin 78712, TX

E-mail: averyholton@gmail.com (Appendix follows $\rightarrow$ ) 


\section{Appendix}

\section{Appendix 1: Survey Sampling International}

The sample was generated by Survey Sampling International (SSI), a research firm specializing in survey research with 30-plus years of experience. SSI's North American online panel consists of more than 1.4 million active households. The panelists were recruited from Web communities, databases, mailing lists, or other collections that have opted to participate in online survey research. SSI seeks to reach both highly visible and hard-to-reach groups on the Internet, such as ethnic minorities, young people, and seniors, to ensure that the sample is representative of the U.S. online population. SSI administers surveys by sending email notifications to its panelists, who were eligible to receive incentives for participation.

\section{Appendix 2: Survey Instrument Development}

In May 2010, 14 undergraduate students from a large southern university representing multiple disciplines par- ticipated in a focus group that allowed them to access news content and applications on new digital devices, including an Apple iPod Touch, an iPad, and two 10-inch Acer netbook computers. All participants were self-described online news users. Participants were asked to indicate their ownership of and familiarity with the various devices in a questionnaire. They were then paired into groups and asked to use and evaluate the various devices for about 40 minutes. Each student spent about 10 minutes with each device. Immediately after the observation period, they were asked to take notes on a variety of questions, including how they liked the navigability and readability of the devices; their ease of use; comfort level; likeability; where they might use such a device; comparisons to other avenues for news (like newspapers); what might be done to improve applications and Web offerings; and whether and what they might pay for such access. 